period. The more complex criterium concern the margin on feeding costs as regards rearing of piglets and the margin on feeding costs and piglet as regards fattening. stage.

The present trend has increased the delay of France relative to its partners at the rearing

Moreover, Germany and to a less extent the Netherlands and Belgium benefit from a more favourable VAT system.

\title{
Economic risk and technical change in pig production
}

\section{F. COLSON}

Institut National de la Recherche Agronomique

Laboratoire d'Etudes Economiques sur les Industries Agricoles

et Alimentaires, Chemin de la Géraudière, 44072 Nantes Cedex

Pig production is characterized by the large variability of economic results due to fluctuation of market prices and to differences in technical efficiency among pig breeders.

Pig farming units are more indebted than the other animal raising systems, but the income is equal or superior to that of the others.

The development of pig production highly depends on the search for new methods or herd management which contributes to reducing the economic risks for pig production investors.

\section{Market prices of slaughter pigs in the E.E.C. : Adjustment before comparison}

\author{
G. DAUMAS \\ Institut Technique du Porc, 34, bd de la Gare, 31500 Toulouse
}

National quotations of slaughter pigs constitute a privileged means of comparison between E.E.C. countries, but their mode of calculation remains highly different. The purpose of the present study was to determine the distorsion factors and to quantify them in four countries : France, Germany, the Netherlands and Denmark in September 1987.

Some factors depend on type qualities defined on the basis of carcass grading scales, and particularly on problems of lean content measurement. The others concern the carcass presentation and the hot-cold rebate, the commercialization stage and the weighting of regional quotations.

Using these elements, it is possible to correct reference quotations to improve their comparison ability. 